This is a preliminary version of a paper to appear in the I.E.A.'s journal Economic Affairs in 2004. Do not quote from, or cite, this paper without permission from the author.

\title{
Making Up History: A Comment on Pratten
}

\author{
By E. Roy Weintraub
}

One should not confuse the opinion I've expressed here with the affectations of certain people who avoid any kind of calculation, people who translate into long sentences what is very briefly expressed by algebra, and adding thus to the length of these operations the lengths of a language which is not made to express them. Such people are a hundred years behind the times. Evariste Galois, De Ste Pelagie, December 1831

Steven Pratten's paper on mathematical formalism presents a critique of mainstream or neoclassical economics from the perspective of Tony Lawson's critical realism. As an historian, I have no particular quarrel with the critique itself, since not only am I uninterested in ontological reflections, but I have no particular interest in either attacking or defending mainstream economics. I do however have an interest in making sure that the history of economics (or historical argumentation itself) is not abused. I also of course have an interest in the nature and history of formalism, having written extensively on this subject for twenty years.

I have two main concerns with Pratten's paper: first, the author has confused ideas about what he calls formalism; and second, he constructs a tendentious history of economics involving an imaginary Cambridge position on mathematical argument in economics, a history of Cambridge economics that bears little relation to any "facts on the ground."

First, there is the issue of formalism. Nowhere in this paper, certainly nowhere in the author's references and apparently in his intellectual experience, is there a definition of "formalism" consistent with that word's use by mathematicians, historians of mathematics, and historians of mathematical economics. Instead Pratten provides a footnote claiming that: 
"The term formalism is used by the Cambridge group in a very broad sense to include all those projects that have pursued the objective of mathematising the subject. This definition includes the attempted axiomatisation of economic theory and particular strategies such as using forms of applied mathematics as economic modelling but is not confined to any one project. Other contributors use the term formalism in a much narrower sense to refer to specific developments since 1940. The Cambridge group with their more encompassing definition are [sic] able to provide a telling commentary on the drive to mathematise economics over the last 200 years..."

The author goes on to suggest that "a closed system is one within which regularities of the form "whenever event or state of affairs $\mathrm{x}$ and event or state of affairs y' obtains. . . [so that] by presupposing formalistic mathematical methods to be always appropriate mainstream economists assume that something at least approximating these sorts of conditions hold in the social realm." This seems to suggest that any mathematical modeling of the social realm is associated with formalistic methods, or "formalism." The difficulty is that the author, and perhaps some of his Cambridge friends (since his paper claims to speak for a newly heralded Cambridge perspective), seem to be the only ones who use the term formalism in this sense. The author, in other passages, seems to associate the axiomatic approach itself with formalism, whether this is mathematical or not. Or, perhaps it is that the author sees formalism as the application or isomorphism of the mathematical model with "the real world." The difficulty of course is that neither "mathematical model" nor "the real world" is well specified in any particular context.

Nevertheless Pratten appears to undercut his own usage when he tells us that "a central problem with much of contemporary economics is the over emphasis on formalism. It is not the use of mathematical methods per se that is the issue of concern but a universalization of formalistic methods combined with a failure to question whether such methods are appropriate to the context in which they are applied." Thus from his larger discussion, it appears that Pratten's formalism is sometimes coextensive with "use of mathematical methods" (even with his "per se"), and it is sometimes rather refers to general modeling practices or strategies.

Formalism works primarily as a pejorative term for Pratten: his preferred usage is equivalent to overuse of mathematics. Now "overuse" is a normative term. Person A's "overuse" is person B's "under use". Thus we have the author's apparent equation of bad mathematics $=$ bad mathematics. This is bad form, and of course unconvincing.

The point is obvious. Formalism is one of those words that really needs definition. It is not sufficient to say that formalism is a bad thing so that all wise heads nod in unison. Formalism has a history, and intellectual historians, as well as historians of economics and historians of mathematics, have been providing such histories. It 
would be useful if the author demonstrated he had read some of them. For example, the author might be startled to realize that historians of mathematics (Israel 1981; Corry 1989, 1996, 1997; Rowe 1994, 1997; Weintraub 2002) are quite adamant that what constituted formalism in the late Victorian period -- Alfred Marshall's middle adulthood as it were -- is not consistent in any way with what formalism meant for mathematicians (those who developed the idea of a "mathematical model") in the first decades of the $20^{\text {th }}$ century, and both notions are inconsistent in many ways with the idea of a mathematical model as it is understood in mathematics today. Mathematics is not a monolith. It changes in its concerns, its conceptions, and in its approach to solving problems that require, in local and contingent circumstances, mathematization. In other words, what constitutes formalism changes as the image of mathematics, mathematicians' sense of what mathematics is about, changes.

Marshall's own mathematics is of the mid $19^{\text {th }}$ century variety, shaped by his and his contemporaries' rather bizarre experiences with the Cambridge Mathematical Tripos examination (Weintraub 2002, 9-40). Marshall himself, in the quotation ${ }^{1}$ with which the author shapes his paper, had an entirely inadequate understanding of then contemporaneous mathematics in 1890 . It cannot be emphasized too strongly that Marshall was really out of date mathematically late in the $19^{\text {th }}$ century. For Marshall to have passed on to his students this notion of what mathematics might provide to economics, even as it no longer served as an adequate image of mathematics, is of course possible. The author appears to believe this, writing: "it is fitting, then, given Marshall's concerns and the skepticism expressed by many of the great Cambridge economists (Keynes, Kaldor, Joan Robinson) regarding the appropriateness of mathematical modeling ..."

The difficulty of course is that Marshall was trained in the 1860s, Keynes was trained around 1900, and Robinson was trained in the 1920s, and all of them had to deal with the issue of mathematical modeling. But mathematical modeling meant something different in each of those time periods. It is really strange for me as an historian, one who had always thought that at least in the Cambridge UK economics tradition, history was taken seriously, to realize the historical lacunae that seem to characterize a Cambridge economics education these days.

My second concern is less a matter of the historical record, and more one of historiography. I offer for comparison a similarly interested, and similarly tendentious, historical reconstruction in monetary theory. I refer to that wonderful nonsense, exposed and fumigated by Don Patinkin (1981), about how the quantity theory of money was taught in the 1920s and 1930s at the University of Chicago, and how with the arrival of the Keynesian revolution, it was only that small light burning on the Chicago Midway that kept the Quantity Theory truth alive over the time that Keynesianism held sway, until Milton Friedman used that small flame to light the monetarist torch which fired up the

\footnotetext{
${ }^{1}$ [The mathematician] uses economic hypotheses for the purpose of mathematical diversions ... his concern is to show the potentialities of mathematical methods on the supposition that material appropriate to their use had been supplied by economic study. He takes no technical responsibility for the material, and is often unaware how inadequate the material is to bear the strains of his powerful machinery (1890: 644).
} 
glorious counter revolution. This Chicago folk tale, as Bentham noted in a different context, is nonsense on stilts. Similarly a history of a Cambridge tradition beginning with Alfred Marshall of opposition to mathematical modeling, consistently critical of mathematical methods in economic analyses that have been developing over two centuries, is nonsense on a pogo stick. It is shoddy scholarship to invent coherent intellectual traditions where none exist.

I have no particular quarrel with the author's contemporaneous castigation of mathematical modeling in economics, for this is a matter for economists to address. But a Habermasian "sprachethik" requires that the historical arguments, and logical distinctions associated with such analyses, should reflect the enlightened conversations of scholars who have addressed such matters in detail. Instead of cultivating a culture of complaint, and reading only those with whom one agrees, Pratten and his Cambridge corealists might read Giorgio Israel (1981; with Ingrao 1990), Joan Richards (1988, 1991), Philip Mirowski (1989, 2002), and (modesty does not forbid) E. Roy Weintraub (1991, 1998, 2002), those who write directly on these matters, instead of just citing other Cambridge authors, and those like Ronald Coase and Mark Blaug whose views were formed a half century ago. Were they to engage such texts, even in disagreement with them, their claims (no matter how useful or interesting) would not be so poorly argued.

Let me give but one example of this. Pratten claims that "this kind of ontologically oriented argument chimes with the insights of numerous earlier Cambridge economists, not just Marshall. Keynes also can be seen as, at least at times, adopting a similar orientation." The author then goes on to argue that Keynes' views were quite clear from both his Treatise of Probability, and from a letter associated with a comment/review which Keynes did not want to do on Tinbergen's League of Nations study. This historical argument is incoherent. Keynes wrote the Treatise on Probability (reflecting the project of Russell and Whitehead) in the first decade of the $20^{\text {th }}$ century, although it wasn't published until much later. Keynes's views on Tinbergen, recorded in the late 1930s, are the opinions of a man in his mid 50s. Why Keynes's opinions on mathematics, formed during his undergraduate time as a student of archaic Cambridge mathematics, should have remained constant over time is not explained, especially since mathematics had changed. More to the point however, Keynes' views were by no means continuous with those of others at Cambridge in the $1930 \mathrm{~s}^{2}$, a position that the author not only fails to recognize, but that should have given him pause about his claim of a unified Cambridge view on formalism.

For instance, in a letter from Harrod to Dennis Robertson dated 3 October 1935 (Besomi 2003, 440-441), Harrod writes "I have before me Econometrica, with its Tinbergen and Kalecki. I suspect that Kalecki is saying something that I have been feeling towards, and I have got to try and find out. But what a paper it is! I also suspect

\footnotetext{
${ }^{2}$ Or even earlier. Note that (Cambridge's) Frank Ramsey's calculus of variations explorations in economics are precisely the kinds of analyses that would have been frowned upon in Cambridge in Pratten's reconstruction of monolithic Cambridge. Or see, for example the letter to Roy Harrod from Ramsey dated 16 September 1929 (Besomi 2003, 110-112) concerning what was to be called the marginal revenue curve.
} 
that economics will sink deeper and deeper into some sort of scholastic morass until we all become Wesley Mitchells. And that is rather gloomy. I just can't become a Wesley Mitchell, so what am I to do? My only ray of sunshine is Maynard's book." This is consistent with the refrain from Harrod, echoed in many of his exchanges, reproduced in his interwar letters to and from Cambridge economists (Besomi 2003), that he and those to whom he was writing (Robertson, Henderson, etc.) simply were not able to understand mathematical argumentation. It was not a matter of ontology, but rather a failure of their education.

These matters have been addressed by others, and the touchstone is, or should be, Rod O'Donnell's (1997) paper on "Keynes and Formalism" in which he first describes two views about Keynes and his relationship to economics presented, or described, or treated, mathematically. O'Donnell then explores in Keynes's published and, much more importantly, unpublished writings Keynes's views. O'Donnell presents several letters by Keynes which have not previously been published, and uses these to present a Keynes who was not unalterably opposed to the use of mathematics, but was rather concerned that the mathematics be "appropriate" to the problem under discussion. It is shocking that Pratten does not refer to O'Donnell.

Let me go a bit. Consider Pratten's argument referring to Keynes's views on Tinbergen. The context in which that view was proffered was an exchange of letters between Harrod and Keynes. I will have to quote this exchange in detail, since it is seldom seen except as a fragment, or told except as a "sound bite". Harrod wrote to Keynes on 6 July 1938 (Besomi 2003, 801-805) stating that

"I'm not sure that I agree altogether with your hostility to the idea of economics as a natural science. . . With regard to Schultz, I intended to indicate that his particular work is probably more or less a waste of time. But this is only to the extent that one admits that the theory of value as set out by Marshall, Walras, Cassel, etc. is played out. This still occupies the central position in any textbook of economics. If on the other hand these equations of static theory are of importance, surely they should be given provisional quantitative significance, even if this had to be re-done from time to time. Just as, surely, one wants to know the value of the Multiplier, even if one also knows that it is subject to both cyclical and secular change. . . While, therefore, I agree more or less about Schultz, I feel that Tinbergen may be doing very valuable work, in trying to reduce this part of theory to quantitative terms. ... [But] I begin to feel that the time has come when I ought to soil my fingers by doing some of this sort of statistical work myself or supervise others in the doing of it. I make a statement about the "acceleration principle." Then Tinbergen comes and says that the facts do not suggest that 
it has had the influence I ascribe to it. Surely one ought not to leave the matter there. To Tinbergen the statistics merely suggested a negative result; to me, if I applied his technique, they might suggest a refinement of my concepts or re-stressing of the importance of one at the expense of the other. I confess all this frightens me a little. I imagine the possibility of a vast amount of time-wasting. But I have a feeling that one ought to take the risk. The trouble with the statisticians I feel is that they are too divorced from theory to derive the full benefit of their own experiments with figures. We have a sort of minor Tinbergen here in the form of Marschak. It is awfully funny to watch Hubert Henderson's reaction to his statistical findings. He thinks the whole thing obvious nonsense. ... If there is to be a developing subject with a lot of workers, competent but not outstandingly expired, who want to find systematic work to do, more or less prescribed by the state of the subject - as in other sciences-I should have thought a mixture of Tinbergen and pure theory was the right answer. ..."

Keynes' point in response to this letter of Harrod is quite startling, even more so when we notice how this exchange of letters between Harrod and Keynes concerning Tinbergen has played a quite important role in the development of a reconstructed Cambridge, and the mythical Cambridge tradition.

"My point against Tinbergen is a different one. In chemistry and physics and other natural sciences the object of experiments is to fill in the actual values of the various quantities and factors appearing in an equation or a formula; and the work when done once and for all. In economics that is not the case, and to convert a model into quantitative formula is to destroy its usefulness as an instrument of thought. Tinbergen endeavors to work out the variable quantities in a particular case, or perhaps in the average of several particular cases, and he then suggest that the quantitative formula so obtained has general validity. . . . All the statisticians tend that way.... The pseudo-analogy with the physical sciences leads directly counter to the habit of mind which is most important for an economist proper to acquire."

Herein, of course, is the problem. It's uncomfortable for economists to have to say it, but Keynes in the 1930s appears quite ignorant about the natural sciences. His view of them, and particularly the idea of a scientific model, reflects a turn-of-thetwentieth century Tripos education in mathematics. That Keynes thought that 
quantitative work in the sciences was a matter of filling in correct values for coefficients in equations strikes a modern reader as bizarre; more importantly of course, it would have appeared bizarre to scientists at the time Keynes was writing. Turing and von Neumann (Mirowski 2001) were already then reconstructing algorithmics as the foundation of logical/scientific inference, while the probabilistic revolution (Krüger 1987) was reconstructing modelling practices in the sciences.

An historian would wish to contextualize Keynes's views by locating them in a particular time and place of his development both intellectually and socially. Recall that in 1938, Keynes was 55 years old, not an age in which one commonly finds an individual embracing new and different ways of thinking, in fields far removed from one's own, especially in fields for which one has a slight repugnance. This obiter dicta by Keynes with respect to Tinbergen is nevertheless taken as another in a series of canonical founding texts of the modern Cambridge tradition, a tradition of arguing that begins with Marshall expressing concern (in his letter to Bowley) about mathematics taking over economics. The tradition then holds that Marshall's student Keynes was similarly concerned (vide that letter about Tinbergen) and passed that on to the younger generation of Cambridge scholars writing in economics (Ramsey? Meade? Champernown?). And today Cambridge has Tony Lawson and his students constructing arguments in that same tradition about the relation between mathematics and economic reality. This narrative may be generally true, but only in the sense that it is not particularly true.

\section{References}

Besomi, D., Ed. (2003). The Collected Interwar Papers and Correspondence of Roy Harrod. Cheltenham UK and Northampton MA, Edward Elgar.

Corry, L. (1989). "Linearity and Reflexivity in the Growth of Mathematical Knowledge." Science in Context 3(2): 409-440.

Corry, L. (1996). Modern Algebra and the Rise of Mathematical Structures. Boston, Birkhauser.

Corry, L. (1997). "David Hilbert and the Axiomatization of Physics (1894-1905)." Archive for History of Exact Sciences, 51: 88-197.

Ingrao, B. and G. Israel (1990). The Invisible Hand: Economic Theory in the History of Science. Cambridge, MIT Press.

Israel, G. (1981). "Rigor and Axiomatics in Modern Mathematics." Fundamenta Scientiae 2: 205-219. 
Krüger, L., G. Gigerenzer, et al., Eds. (1987). The Probabilistic Revolution: Volume 2, Ideas in the Sciences. Cambridge, MIT Press.

Mirowski, P. (1989). More Heat Than Light. New York and Cambridge, Cambridge University Press.

Mirowski, P. E. (2002). Machine Dreams. Cambridge, Harvard University Press.

O'Donnell, R. (1997). Keynes and Formalism. A 'Second Edition' of The General Theory.

G. C. Harcourt and P. A. Riach. London and New York, Routledge. 2.

Patinkin, D. (1981). Essays On and In the Chicago Tradition. Durham, N.C., Duke University Press.

Richards, J. L. (1988). Mathematical Visions: the Pursuit of Geometry in Victorian England. San Diego, Academic Press.

Richards, J. L. (1991). "Rigor and Clarity: Foundations of Mathematics in France and England, 1800-1840." Science in Context 4(2).

Rowe, D. E. (1994). The Philosophical Views of Klein and Hilbert. The Intersection of History and Mathematics. S. Chikara, S. Mitsuo and J. W. Dauben. Boston, Birkhauser.

Rowe, D. E. (1997). "Perspective on Hilbert." Perspectives on Science 5(4): 533-570.

Weintraub, E. R. (1991). Stabilizing Dynamics. New York, Cambridge University Press.

Weintraub, E. R. (1998). "Axiomatiches Mißverständnis." Economic Journal 108 (November): 1837-1847.

Weintraub, E. R. (2002). How Economics Became a Mathematical Science. Durham, NC, Duke University Press. 